\title{
Cine y Educación: modos de ver y pensar la adolescencia a través de su representación en el cine de Larry Clark
}

\author{
Ines Martins ${ }^{1}$ \\ Santiago Estaún ${ }^{2}$
}

\section{Resumen}

El presente artículo tiene como objetivo analizar el cine como medio de expresión y representación de un determinado contexto sócio-histórico y como herramienta pedagógica en la formación de sujetos críticos y activos en su contexto social. En primer lugar, se ha analizado la representación de la adolescencia en las películas Kids y Ken Park de Larry Clark, a través del análisis semiótico del film. Posteriormente, se han contrastado las divergencias o coincidencias entre la representación de la adolescencia norteamericana en el cine y los datos encontrados en los estudios científicos sobre la misma. De manera general se puede concluir que: 1) el cine es un vehículo de comunicación, influencia y re-presentación sociocultural y como tal está condicionado por su entorno y reflejará elementos significativos de su época. 2) la función social del cine le convierte en una excelente herramienta pedagógica en la educación del pensamiento crítico, y sujetos activos en el acto de ver, pensar, interpretar y analizar una determinada realidad.

Palabras clave: cine, representación social, adolescencia, semiótica, educación.

\section{Cinema and Education: ways of seeing and thinking about adolescence through its representation in the cinema of Larry Clark}

\section{Abstract}

The aim of the present article is to analyze cinema as a means of expression and representation of a specific socio-historical context, as well as a pedagogical tool in the formation of critical subjects active in their social context. In the first place, the representation of adolescence in Larry Clark's Kids and Ken Park films was analyzed through a semiotic analysis. Subsequently, the divergences or coincidences between the representation of American adolescence in the cinema, together with the data found in the scientific studies on the subject, have been considered and closely contrasted. In a general way, as a conclusion, it can be stated that:

1 Doctora en Psicologia de la Comunicación por la Universidad Autónoma de Barcelona. Profesora titular y Coordenadora Acádemica del Grado en Diseńo del Centro Universitario Internacional de Barcelona (UNIBA) de la Universidad de Barcelona (UB). E-mail: imartins@unibarcelona.com

2 Doctor en Filosofía y Letras por la Universidad Autónoma de Barcelona y doctor en Psicología por la Universidad de Paris V René Descartes. Catedráctico y profesor emérito de Psicologia de la Percepción en la Universidad Autónoma de Barcelona (UAB). E-mail: santiago.estaun@uab.cat 
1) the cinema is a vehicle of communication, influence and socio-cultural re-presentation and, being conditioned by its own environment, will reflect significant elements of its time. 2) owing to the social functions involved, the cinema can be understood as an excellent pedagogical tool in the education of critical thinking, and active subjects in the act of seeing, thinking, interpreting and analyzing a certain reality.

Keywords: cinema, social representation, adolescence, semiotics, education.

Cinema e Educação: modos de ver e pensar sobre a adolescência por meio da sua representação no cinema de Larry Clark

\section{Resumo}

O presente artigo tem como objetivo analisar o cinema como meio de expressão e representação de um contexto sócio-histórico específico e como ferramenta pedagógica na formação de sujeitos críticos e ativos em seu contexto social. Em primeiro lugar, analisamos a representação da adolescência nos filmes Kids e Ken Park de Larry Clark, por meio da análise semiótica da imagem fílmica. Posteriormente, contrastamos as divergências ou coincidências entre a representação da adolescência norte-americana no cinema e os dados obtidos nos estudos científicos sobre a mesma. Em geral, pode-se concluir que: 1) o cinema é um veículo de comunicação, influência e representação sócio-cultural, e como tal está condicionado pelo seu entorno e refletirá o elemento essencial de sua época. 2) a função social do cinema o transforma em uma excelente ferramenta pedagógica na educação do pensamento crítico, e em sujeitos ativos no ato de ver, pensar, interpretar e analisar uma determinada realidade.

Palavras-chave: cinema, representação social, adolescência semiótica, educação.

\section{Introducción}

El cine nace del deseo incansable del ser humano de captar, registrar y representar, lo más cercano posible la realidad cotidiana y, por ello, su función social está marcada por la representación de la sociedad y por la historia del hombre. Es, a la vez, espectáculo y acción social, como se manifiesta en los movimientos vanguardistas, el neorrealismo, la nouvelle vague, el cinema verité, el cine underground y el cinema novo, entre otros. El cine es un reflejo de la sociedad, de la vida del hombre y de su convivencia con los demás; refleja en sus guiones historias que parecen a veces fantasiosas pero que en más de una ocasión - cuando al ver el film recordamos a algún amigo o familiar nos damos cuenta de que la realidad supera a la ficción.

De los medios de comunicación social, priorizamos el cine en cuanto sistema de representación cultural y del imaginario social, que ordena codifica y reelabora los contenidos discursivos, dotándolos de sentido, funciones, 
y que no sólo reproduce la realidad, sino también la define. El cine, al actuaren el campo simbólico, en la creación y recreación de representaciones, de imágenes significantes, construyendo una realidad virtual, estableciendo una relación con lo real y elaborando un imaginario específico, no sólo produce imágenes, sino ideas, ideologías, que conforman tanto las identidades individuales como las nacionales y culturales. Consecuentemente, podemos decir que el cine ejerce su influencia sobre el individuo en formación, en la construcción de su identidad, convirtiéndose en un agente de socialización - indirecta, pero de gran importancia - de niños, adolescentes, jóvenes y adultos. Los adolescentes reciben información sobre sí mismos y sobre su entorno, no sólo mediante las relaciones sociales sino también mediante imágenes mediáticas, creando en conjuntouna representación muy concreta de esta realidad. Resulta difícil comprender las actitudes y valores de los adolescentes contemporáneos sin considerar la profunda influencia de los mass media - y en particular del cine - en sus vidas. Además, la variedad de contenidos que ofrecen los medios demandan una reconstrucción personal de estos mensajes (MARTINS y ESTAÚN, 2011).

Por todo ello, consideramos al cine comouna excelente herramienta pedagógica si sabemos educar la mirada, el pensamiento crítico y sujetos activos en el acto de ver, pensar, interpretar y analizar una determinada realidad.

El estudio de las representaciones de la adolescencia en el cine integrados factores: el interés por el cine como medio de expresión y representación de las culturas y el interés del cine como herramienta pedagógica en la formación de sujetos críticos y activos en su contexto social. De acuerdo con Duarte (2017), analizar películas ayuda a profesores y estudiantes a comprender la forma como diferentes culturas educan/forman las nuevas generaciones. Es un nuevo mundo, construido en y por el lenguaje cinematográfico, que se abre para nosotros cuando nos disponemos a mirar las películas como fuentes de información. La mirada del cine a determinados temas contemporáneos nos invita y nos enseña, también, a mirarlo desde otra perspectiva. La experiencia de los sujetos con el cine contribuye para el desarrollo de la "competencia para ver" (BOURDIEU, 1979 citado por DUARTE, 2017), es decir, nos lleva a comprender y apreciar la realidad como una práctica social. En la misma perspectiva que Duarte, creemos que el cine y la educación son formas de socialización de los individuos e instancias culturales que producen saberes, identidades, formas diversas de ver y comprender el mundo, subjetividades. 
Otro aspecto importante a señalar es que el análisis semiótico del cine nos permite en el ámbito educativo, trabajar con los estudiantes el lenguaje cinematográfico, es decir, los modos por los cuales el director/a ha construido la narrativa - planos, secuencias, diálogos, personajes, etc. Según Amorin y Bueno (2011), el contacto con otras formas de pensar, ver y vivir el mundo (la del director del cine), nos abre un abanico de posibilidades de entenderlo desde diferentes perspectivas. No hay una única verdad - que en este caso estaría representada en la imagen - sobre un determinado aspecto de la realidad, así como también las lecturas que realizamos de las imágenes deben ser múltiples, puesto que éstas están mediadas no sólo por el que produce la imagen, sino también por el que la recibe.

De esta forma, nos interesa investigar la capacidad polisémica de la imagen, las tensiones y dinámicas implicadas en sus narrativas y sus relaciones con lo real. Dotar la imagen de la posibilidad de ofrecernos otros modos de pensar - más allá de lo que ya sabíamos o acreditábamos - de un determinado contexto sociohistórico. La posibilidad de vivenciar una realidad atenuada en el acto de asistir a una película puede llevar a momentos de reflexión que interfieren en la forma de dar sentido a la vida. Y este es nuestro mayor interés del cine como herramienta didáctica en las prácticas pedagógicas.

Si el cine es una fuente de información de valores y representa o refleja la realidad de un determinado contexto sociohistórico, entonces las formas de representación deben ser entendidas como el producto de las necesidades y aspiraciones sociales del grupo al que representa. Si el cine es un vehículo de representación de la realidad (BAZIN, 2004), nos interesa indagar sobre las relaciones entre el carácter básico de una época y su reproducción por el cine.

Según Busquets (1977), las imágenes comunican ideas. La función comunicativa del signo-imagen engloba una doble función, la función informativa (respecto de las cosas o realidades) y la función expresiva o propiamente comunicativa (resultado de la intención del autor). Así, pues, la imagen en sentido amplio, representa la realidad en sí, pero al mismo tiempo muestra el conocimiento que el autor tiene de la misma y cómo concibe su representación, a veces sin solución de continuidad con aquella. De esta forma, las películas son la representación visual de las imágenes mentales del autor de dicha representación visual. Busquets realiza el análisis de los conceptos o contenidos en imágenes, es decir, la interpretación del mensaje en las imágenes, mediante el proceso codificación-decodificación de ésta, de 
cómo se constituyen, sus objetivos, sus distorsiones y su influencia en los receptores. Clasifica la imagen como un signo no convencional, donde cada una, en principio es polisémica, es decir, implica una gama de significados y su lectura es múltiple. De aquí la importancia de saber leer la imagen, a fin de detectar las posibles deformaciones y manipulaciones de la realidad concebidas en este proceso.

Leer es interpretar un signo, identificar su significación. Como la imagen es a la vez representación de contornos de realidades y expresión de la mente de su autor, el cual se expresa efectuando una particular representación, leer la imagen querrá decir identificar no la significación de las cosas, sino la significación de la imagen en cuanto tal. Leer imágenes es captar la idea del autor de las mismas expresada en y por ella. (BUSQUETS, 1977, p. 198).

Busquets (1977) propone un método de lectura de las imágenes consistente en el análisis de los dos componentes de la comunicación: el Qué comunica (C1) y el Cómo lo comunica (C2), y su significación conjunta. Esquemáticamente tenemos 4 niveles de lectura: El primero sería el del acontecimiento en sí. A este nivel es preciso preguntarse ¿Qué significa la cosa representada en la imagen?, ¿Qué dice esa precisa imagen?, ¿Qué representa?, que viene a ser los C1 de la imagen. Aquí los signos son considerados en cuanto cosas y no en su forma significante, pero también tienen su acción y significación. La acción es representar lo que estaba fuera del signo en el momento de la toma y la significación es aquella que asume dicha representación. Pero la acción y la significación de la cosa en sí pueden ser alteradas en la imagen o reproducción de la misma. Este primer nivel se halla constituido por los núcleos narrativos. Busquets define el núcleo narrativo como

aquellos bloques de acontecimiento en los que puede dividirse la narración fílmica, a según qué niveles, y en los que sobresale/n el/los protagonista/s o héroe/s de la misma." Se constituye una unidad que se verifica en cualquier nivel piramidal de lectura del film. Los núcleos narrativos se relacionan entre sí a través de los ejes estructurales de modo que su conjunto cobra una nueva dimensión significativa en la narración fílmica precisamente por su relación estructural, es decir, son los "problemas" o líneas de fuerza en torno a los que estos se organizan. (BUSQUET, 1977, p. 212). 
El segundo nivel de lectura lo constituye la narración fílmica del acontecimiento. En este nivel tenemos la lectura de la acción de la narración para llegar a una determinada significación surgida de esa realización peculiar; es decir, la significación de los Cómos, de los modos en que los C1 se presentan en la imagen (Ej. Primeros planos, cámaras lentas, picado o contra picado, tipos de música, etc.). Aquí tenemos los $\mathrm{C} 2$ que vienen a ser los modos de representar los $\mathrm{C} 1$, que no son sino los modos de deformarlos (técnica o expresivamente). De este modo, la pregunta que se hace es ¿Qué significa la representación de la cosa que se ha efectuado? (acción y significación de los C2).

El tercero nivel de lectura sería el de la narración o racconto, que viene a ser los modos concretos de la imagen con los que el suceso o acontecimiento se ha tramado en ella. Aquí tenemos la significación de la imagen en su totalidad que viene dada por la suma de los $\mathrm{C} 1+\mathrm{C} 2$. La pregunta entonces sería ¿Por qué ha optado por unos modos determinados en su representación y no por otros? Todos los modos elegidos por el autor confluyen hacia una unidad expresiva - la idea central - que no es otra que la idea que quiere comunicar el autor mediante sus imágenes. En este nivel tenemos la significación mediata o temática que consiste en el producto de toda la gama de los $\mathrm{C} 1$ y C2 que presenta la imagen y que no se agota a nivel inmediato.

El cuarto y último nivel de lectura viene dado por los fondos mentales del autor y se caracteriza por la lectura global de lo que la imagen comunica, es decir, es la respuesta global de los Porqués en el nivel anterior, pero desde una perspectiva distinta a la de la indagación significativa. Aquí analizaremos los Qué-Cómo-Porqué del aspecto narrativo y los Qué-Cómo-Porqué del aspecto temático.

En síntesis, para la lectura del film, tenemos que leer la narración a través de la acción del suceso o acontecimiento de ésta y la significación de dicho suceso para llegar (mediante la universalización) a la significación inmediata de la narración y formulación de la idea central del autor. Para esto, la lectura se hace de manera piramidal, es decir, por el hecho de la duración, del antes y después, una imagen conectada a otras adquiere nuevos contenidos significativos, nuevos <Qués> y nuevos <Cómos>, que confluyen hacia un contenido unitario - el de toda la obra. En los niveles más bajos de la pirámide tendríamos las significaciones de cada fotograma y de todo su conjunto; en los más altos, la idea comunicada por el autor que se apoya en los fondos mentales, como se indica en la siguiente figura 1 . 
Fig. 1 - Esquema Piramidal del Proceso de Lectura del Film Señalando la Correlación entre los Niveles de Significación y los Niveles de Lectura
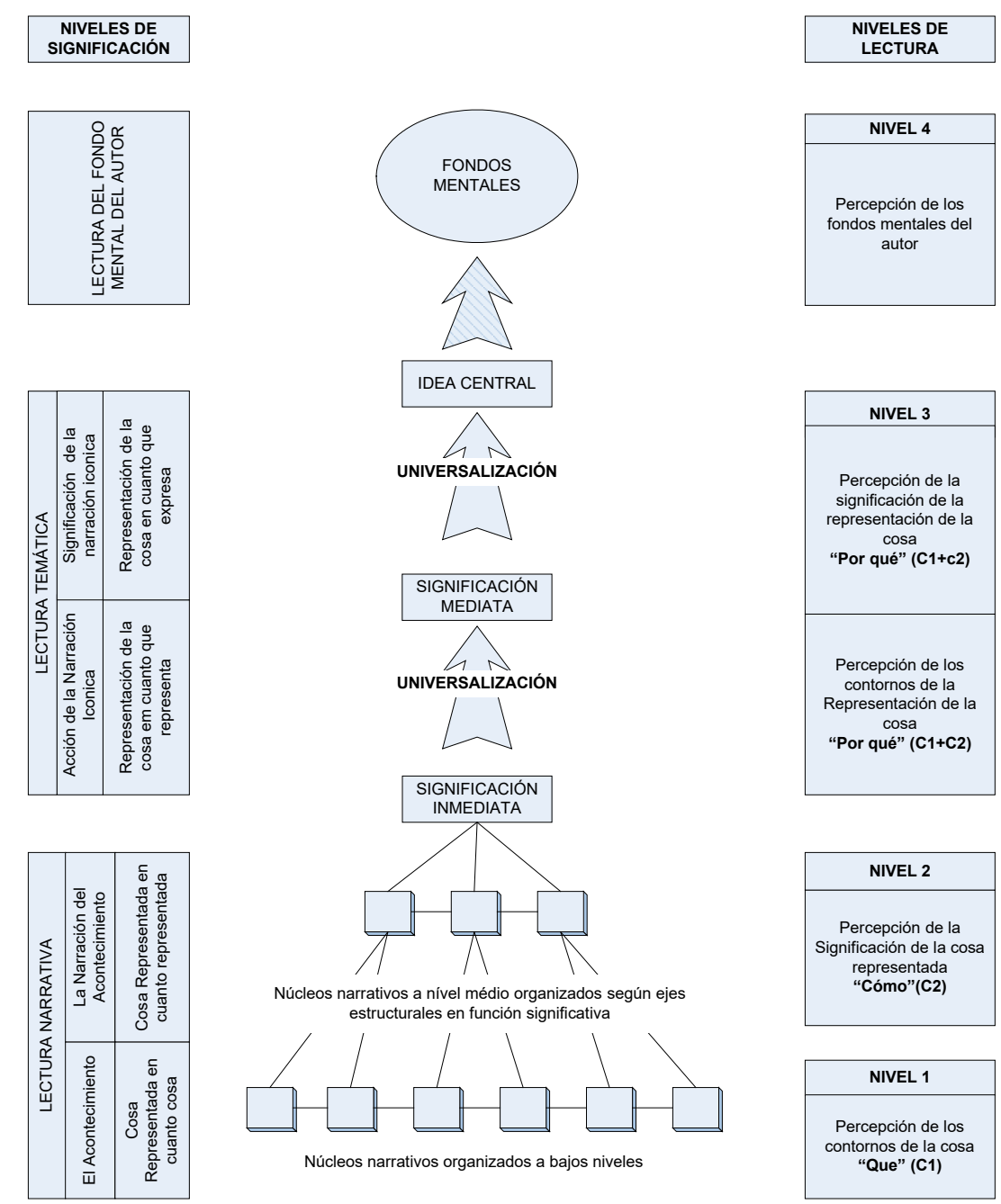

Nos proponemos presentar un ensayo de análisis cinematográfico, siguiendo la metodología propuesta por Busquets, de un caso específico como es la representación de la adolescencia norteamericana en el cine a través 
de la filmografía de Larry Clark, ${ }^{3}$ más específicamente ¿Cómo Larry Clark retrata la adolescencia norteamericana?, ¿ ¿Se da correspondencia entre lo que él representa y lo que ocurre en la realidad de estos jóvenes?, ¿En qué medida?, ¿El cine, en cuanto producción artística y expresión cultural cumple con la función social de espejo de esta realidad y de herramienta educativa?

Los EEUU han sido, desde el nacimiento del cine, uno de los países que más han contribuido a su desarrollo y expansión. Los films norteamericanos nos enseñan - con más o menos realismo - su cultura, formas de vida e ideología. En el caso del cine de Larry Clark, y según el propio autor, su filmografía es un espejo de las problemáticas que sufren los y las adolescentes estadounidenses contemporáneos y una crítica a esta sociedad. En la visión del autor, estos adolescentes - en su mayoría de clase media y alta - se encuentran perdidos, alienados, sucumbiendo a las drogas y a la violencia, sin referencias paternas y donde la institución familiar ha fracasado, así como también la propia sociedad norteamericana. El autor muestra una creciente cultura desinteresada de todo valor moral donde el sexo sin amor y las drogas son el escape ideal de los problemas del mundo. Son adolescentes con complicadas historias pasadas y presentes que vagan por los márgenes de la acomodada sociedad burguesa estadounidense, adormecidos por las drogas y por lo que les proporciona, built in, el American way of life: Televisión, coches, consumismo, incomunicación.

Se pretende, en primer lugar, conocer no sólo la eventual representación de la adolescencia de Larry Clark sino también qué aspectos de la realidad de estos adolescentes está representada en sus films y, en segundo lugar, trabajar el cine como una herramienta educativa ofreciendo la posibilidad de aplicar la metodología de Busquets mencionada en el contexto del aula, con el fin de analizar la(s) realidad(es) en conjunto con los adolescentes y dotarles de herramientas para fomentar la reflexión y el desarrollo del pensamiento crítico.

3 Larry Clark, nacido en 1943 en Tulsa, Oklahoma es considerado como uno de los mejores directores de fotografía del último cuarto de siglo y es a partir de la publicación en 1962 de su libro Tulsa, queClark ha estado siempre interesado en el "realismo". El libro está compuesto por explícitas fotografías tomadas por el autor y sus amigos y, en general, mostrando la decadencia de la juventud de la época. Desde entonces, el autor ha editado varios libros, entre estos, Teenage Lust de 1982 y Perfect Childhood de 1992 - en los que Clark retrata provocativamente temas como cuerpo y sexualidad en jóvenes adolescentes. 


\section{Metodología}

De conformidad con nuestro propósito se han seleccionadodel corpus filmico de Larry Clark las películas de mayor audiencia y crítica: Kids, ganadora del Cannes de 1995 y Ken Park de 2002, con guiones escritos por un adolescente (Harmony Lorine). Kids aborda el tema del Sida y Ken Park gira en torno del tema central del conflicto entre padres e hijos adolescentes.

Para el análisis fílmico de las películas, se ha utilizado la metodología propuesta por Luis Busquets (1977), ${ }^{4}$ de conformidad con lo descrito, por su interés pedagógico.

El criterio de codificación de los bloques narrativos fue la elección de los contenidos relacionados con la representación de la adolescencia en ambas películas. Identificar núcleos narrativos significa identificar la narratividad en función temática, es decir, leer la imagen y éste será nuestro instrumento de análisis, sin olvidar que para ser útil a la interpretación, debe complementarse con la historia y la cultura de la sociedad que le da origen.

De igual modo, se han contrastado los datos del análisis fílmico con los estudios psicológicos y sociológicos sobre la adolescencia como período evolutivo, especialmente la adolescencia norteamericana del período de las películas (década de los 90 a 2002), para contrastar las divergencias o coincidencias entre representación de la adolescencia norteamericana contemporánea en el cine de Clark y los datos encontrados en los libros y artículos científicos.

\section{Resultados}

De la película Kids, se han analizado un total de 16 núcleos narrativos y de la película Ken Park 22 núcleos narrativos. En la filmografía de Clark encontramos ejes temáticos vinculados al tema de la adolescencia, como: la decadencia de la sociedad norteamericana, la destrucción de las relaciones familiares, las raíces de la violencia, la sexualidad, el uso de drogas, el grupo y la construcción de la identidad en la adolescencia contemporánea. Temas abordados desde diferentes perspectivas, pero con coincidencias. La tabla

4 Para una lectura del film, Busquets se sirve del esquema metodológico del profesor Taddei, N. director del Centro Internazionale dello Spettacolo e della Comunicazione, el cual centra sus investigaciones en el programa "Educar para la imagen con la imagen"- Trattato di Teoria cinematografica. I: L'immagine. I7. Milán, 1962; Lectura strutturale del film. I7, Milán, 1964; Metodica crítica e metodología critica del film. Cineforum, Venecia, 1964. 
1 presenta los tópicos encontrados en los niveles 3 y 4 de análisis de los núcleos narrativos y sus coincidencias.

Tabla 1- Comparativa del análisis filmográfico Niveles 3 y 4 de lectura

\begin{tabular}{|c|c|c|}
\hline Tópicos & Kids & Ken Park \\
\hline Tema central & Sexualidad en la Adolescencia. & $\begin{array}{c}\text { Fracaso de la Institución } \\
\text { Familiar. }\end{array}$ \\
\hline SEXUALIDAD & $\begin{array}{l}\text { - Sexo como objeto de } \\
\text { placer inmediato y evasión } \\
\text { de problemas. } \\
\text { - Sexo como el único } \\
\text { objetivo de vida. } \\
\text { - Conductas de riesgo: } \\
\text { transmisión del SIDA. } \\
\text { - Curiosidad y deseo sobre } \\
\text { el cuerpo del otro. } \\
\text { - Primeras relaciones } \\
\text { sexuales. } \\
\text { - Virginidad como símbolo } \\
\text { de pureza y de sexo limpio. } \\
\text { - Imagen corporal. }\end{array}$ & $\begin{array}{l}\text { - Sexo como objeto de } \\
\text { placer inmediato y } \\
\text { evasión de problemas. } \\
\text { - Sexo como el único } \\
\text { objetivo de vida. } \\
\text { - Conductas de riesgo: } \\
\text { sexo sin protección. } \\
\text { - Curiosidad y deseo sobre } \\
\text { el cuerpo del otro. } \\
\text { - Sexualidad } \\
\text { patológica (incesto, } \\
\text { sadomasoquismo, } \\
\text { violación, perversión). }\end{array}$ \\
\hline FAMILIA & $\begin{array}{l}\text { - Fracaso de la institución } \\
\text { familiar. } \\
\text { - Ausencia de afecto, control } \\
\text { y supervisión adulta. } \\
\text { - Ausencia de figura paterna } \\
\text { y/o de autoridad. }\end{array}$ & $\begin{array}{l}\text { - Fracaso de la institución } \\
\text { familiar. } \\
\text { - Relaciones familiares } \\
\text { basadas en: indiferencia, } \\
\text { agresividad, falta de } \\
\text { respeto, rechazo y } \\
\text { creencias religiosas. } \\
\text { - Padres retratados } \\
\text { como: irresponsables, } \\
\text { sin autoridad y } \\
\text { corresponsables de } \\
\text { los problemas de los } \\
\text { adolescentes. }\end{array}$ \\
\hline
\end{tabular}




\begin{tabular}{|c|c|c|}
\hline Tópicos & Kids & Ken Park \\
\hline GRUPO & $\begin{array}{l}\text { - Grupo de pares como el } \\
\text { único referencial. } \\
\text { - Identificación en cuanto } \\
\text { grupo de género, edad y } \\
\text { clase social. } \\
\text { - Presencia de pandillas y } \\
\text { actos violentos. }\end{array}$ & $\begin{array}{l}\text { - Grupo de pares como el } \\
\text { único referencial. } \\
\text { - Identificación en cuanto } \\
\text { grupo de edad y clase } \\
\text { social. } \\
\text { - Presencia de grupos } \\
\text { juveniles }\end{array}$ \\
\hline DROGAS & $\begin{array}{l}\text { - Drogas como objeto de } \\
\text { placer inmediato y evasión } \\
\text { de problemas. } \\
\text { - Utilizada como ritual de } \\
\text { entrada y de pertenencia al } \\
\text { grupo. } \\
\text { - Símbolo de poder. }\end{array}$ & $\begin{array}{l}\text { Drogas como objeto } \\
\text { de placer inmediato y } \\
\text { evasión de problemas }\end{array}$ \\
\hline
\end{tabular}

Kids constituye la primera obra fílmica de Larry Clark. El tema central es la sexualidad en la adolescencia, para quienes el placer de la sexualidad es casi el único elemento válido en una existencia llevada al límite. Este film muestra la vida de un grupo de adolescentes prácticamente autónomos respecto de cualquier figura adulta y fuera de toda institución. Viven una única dimensión temporal: el presente, como si sus identidades se constituyeran únicamente en relación a su grupo de pares con quienes comparten el gusto por el consumo de alcohol, drogas y sexo. Son irresponsables, ufanos de ser propietarios de sus cuerpos pero no de sus consecuencias, adictos a la droga ya la tribu como únicos elementos colectivos, brutalmente violentos y carentes de cualquier código ético. Se resalta, una juventud descontextualizada, viviendo en un vacío histórico, político y cultural.

En Kids, los adolescentes pertenecen a la clase social baja, en Ken Park provienen de familias de clase media-alta. A pesar del cambio de posición social, Larry Clark vuelve a retratar un mundo juvenil en el que el sexo (aquí mucho más explícito), la violencia, las drogas y el vivir al máximo (aunque sea con rumbo a ninguna parte) son los protagonistas, ańadiéndose la figura de los progenitores, igual de perdidos que sus hijos y además son los máximos responsables de las situaciones que se desencadenan en pantalla.

En Ken Park, la violencia sexual y moral es la materia narrativa y contamina todas las formas de relación. Los jóvenes practican el sexo para 
aislarse del mundo descentrado en el que les ha tocado vivir y fantasean - en la última escena de la película - con un mundo en el cual sólo exista el placer y el amor a través del sexo.

La temática familiar en Kids es inexistente. Clark explora con crudeza una juventud norteamericana que vive en completo letargo. Todos los personajes evidencian una profunda carencia de valores y principios. Son marginales, pero no se rebelan, ni cuestionan nada. No piensan, están vacíos y sus padres están vacíos con un insípido rol de padres. Cada adolescente se halla violentamente sólo, aburridos con comportamientos de adultos. Son adolescentes que pasan el día drogándose, ejerciendo conductas violentas sin cuidado alguno por la vida, ni les interesa nada del otro.

A diferencia de Kids, Ken Park representa el ataque más rotundo y directo del director contra la institución familiar y la sociedad norteamericana, fallidas. Los padres son retratados como inmorales e irresponsables y se dedican a hacer la vida imposible a sus propios hijos, siendo meras figuras de autoridad vacía. En Ken Park los progenitores de los protagonistas condicionan con sus actos - locura bíblica de uno de los padres, borrachera permanente del otro, búsqueda de la eterna juventud de la madre de una de laschicas que no duda en acostarse regularmente con el novio de ésta - la incomodidad e insatisfacción de los jóvenes.

Larry Clark retrata la presencia de grupos juveniles como resultado de personas que se aproximan por la identificación común a rituales y elementos de la cultura que expresan valores y estilos de vida, moda, música, con el predominio de cierta vestimenta y accesorios, maneras de hablar y de moverse, lugares que frecuentan. Tanto en Kids como en Ken Park, son adolescentes que practican skate, escuchan rock y RAP, look informal y descuidado, frecuentan las discotecas y se drogan. Viven el momento y nada más; se interesan más por la estética que por la ética, lo que revela un estado de anomia y ausencia de valores.

El consumo de drogas por los adolescentes y sus consecuencias es un tema presente en la filmografía de Clark. El objetivo es la satisfacción inmediata y la huida de los problemas. La droga circula libremente entre los jóvenes, produciéndose un estado de aturdimiento y permisividad para el todo vale. Jóvenes sin códigos éticos, que poseen sus propias leyes basadas en la violencia y la transgresión. En Kids vale todo para tener una relación sexual. La droga es, también, utilizada como un ritual de iniciación y perte- 
nencia al grupo, como en la escena de la fiesta en que los niños fuman y se sienten como los adolescentes.

La representación y percepción que Larry Clark tiene de la adolescencia norteamericana de los años contemporáneos de su filmografía, de acuerdo con la metodología de Busquets, es conveniente y necesario que se contraste con los datos científicos sobre el desarrollo de la persona y, en particular, de los adolescentes norteamericanos contemporáneos a Larry Clark y descritos por él. Se constataron coincidencias y divergencias expuestas en la tabla 2:

Tabla 2 - comparativa entre los estudios sobre la adolescencia norteamericana y su representación enel cine de Larry Clark

\begin{tabular}{|c|c|c|}
\hline & $\begin{array}{l}\text { MARCO TEÓRICO SOBRE LA } \\
\text { ADOLESCENCIA }\end{array}$ & $\begin{array}{c}\text { REPRESENTACIÓN DE LA } \\
\text { ADOLESCENCIA EN EL } \\
\text { CINE DE LARRY CLARK }\end{array}$ \\
\hline 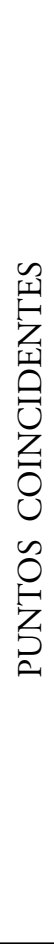 & $\begin{array}{l}\text { Cambios de actitud respecto al } \\
\text { comportamiento sexual de los } \\
\text { adolescentes norteamericanos: } \\
\text { - Precocidad en las relaciones } \\
\text { sexuales (TROTÓN, } 1990 \\
\text { citado en SANTROCK, } \\
\text { 2004; MILLAR y } \\
\text { KING, 1993 citado en } \\
\text { SANTROCK, 2004) } \\
\text { - Aumento de la actividad } \\
\text { sexual; embarazos y } \\
\text { transmisión del SIDA } \\
\text { (ROCHE y RAMSBEY, } \\
\text { 1993 citado en } \\
\text { SANTROCK, 2004; } \\
\text { ALAN GUTTMACHER } \\
\text { INSTITUTE, 1995-1998; } \\
\text { CENTERS FOR DISEASE } \\
\text { CONTROL AND } \\
\text { PREVENTION, 2001; } \\
\text { SONENSTEIN, PLECK y } \\
\text { KU, 1989). }\end{array}$ & $\begin{array}{l}\text { Precocidad en las relaciones } \\
\text { sexuales. } \\
\text { Embarazo y propagación de } \\
\text { enfermedades sexualmente } \\
\text { transmitidas en la } \\
\text { adolescencia. }\end{array}$ \\
\hline
\end{tabular}




\begin{tabular}{|c|c|c|}
\hline & $\begin{array}{l}\text { MARCO TEÓRICO SOBRE LA } \\
\text { ADOLESCENCIA }\end{array}$ & $\begin{array}{c}\text { REPRESENTACIÓN DE LA } \\
\text { ADOLESCENCIA EN EL } \\
\text { CINE DE LARRY CLARK }\end{array}$ \\
\hline \multirow{3}{*}{ 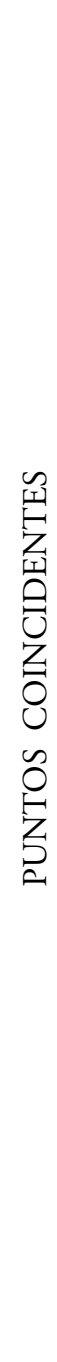 } & $\begin{array}{l}\text { - Conflictos familiares: } \\
\text { - Disminución del control y } \\
\text { supervisión paternos sobre } \\
\text { los adolescentes y escasez de } \\
\text { diálogo entre padres e hijos. } \\
\text { (MILLAR et al., } 1986 \text { citado } \\
\text { en SANTROCK, 2004; } \\
\text { PETTIR et al., 2001) } \\
\text { - Problemáticas presentadas } \\
\text { por los adolescentes asociadas } \\
\text { a los conflictos familiares: } \\
\text { delincuencia juvenil, } \\
\text { abandono escolar, embarazo } \\
\text { en la adolescencia y uso de } \\
\text { drogas (RICHARDSON } \\
\text { et al., 1989; SANTROCK, } \\
\text { 2004). }\end{array}$ & $\begin{array}{l}\text { Relaciones familiares casi } \\
\text { inexistentes o basadas en la } \\
\text { falta de diálogo, supervisión } \\
\text { y afecto. } \\
\text { - Padres como } \\
\text { corresponsables del } \\
\text { surgimiento de conductas } \\
\text { problemáticas en los } \\
\text { adolescentes. }\end{array}$ \\
\hline & $\begin{array}{l}\text { Aumento del consumo } \\
\text { de drogas en edades más } \\
\text { tempranas (PETERSON, } \\
\text { 1994; DIELMAN, SHOPE } \\
\text { y BUTCHAT, 1990; } \\
\text { JOHNSTON, O’MALLEY y } \\
\text { BACHEAN, 2001). }\end{array}$ & - Uso abusivo de drogas \\
\hline & $\begin{array}{l}\text { - Aumento de la delincuencia } \\
\text { juvenil (WALTER, } 1998 \\
\text { citado en SANTROCK, } \\
\text { 2004; CENTER FOR } \\
\text { DISEASE CONTROL } \\
\text { AND PREVETION, } \\
\text { 2000). }\end{array}$ & - Delincuencia juvenil \\
\hline
\end{tabular}




\begin{tabular}{|c|c|c|}
\hline & $\begin{array}{c}\text { MARCO TEÓRICO SOBRE LA } \\
\text { ADOLESCENCIA }\end{array}$ & $\begin{array}{c}\text { REPRESENTACIÓN DE LA } \\
\text { ADOLESCENCIA EN EL } \\
\text { CINE DE LARRY CLARK }\end{array}$ \\
\hline \multirow{2}{*}{ 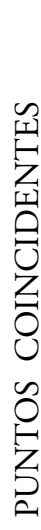 } & $\begin{array}{l}\text { - Aumento del índice de } \\
\text { suicido (FLEMING, } \\
\text { BOYLE y ORFORD, 1993; } \\
\text { NATIONAL CENTER FOR } \\
\text { HEALTH STATISC, 1998). }\end{array}$ & - Suicidio en la adolescencia. \\
\hline & $\begin{array}{l}\text { - Cambios en la sociedad: crisis } \\
\text { contemporánea de la cultura } \\
\text { (BALARDINI, 2019). }\end{array}$ & $\begin{array}{l}\text { - Sociedad Americana } \\
\text { representada como hipócrita, } \\
\text { consumista, individualista } \\
\text { y alienada. Jóvenes sin } \\
\text { perspectivas futuras. }\end{array}$ \\
\hline \multirow{4}{*}{ 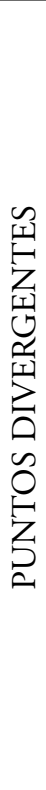 } & $\begin{array}{l}\text { - Adolescencia definida desde } \\
\text { la perspectiva sociohistórica } \\
\text { (LEVI, y SCHIMIT, 1996; } \\
\text { OLIVA, 2003). }\end{array}$ & $\begin{array}{l}\text { - Adolescencia constituida } \\
\text { desde la perspectiva de la } \\
\text { sexualidad. }\end{array}$ \\
\hline & $\begin{array}{l}\text { Familia como agente de } \\
\text { socialización y transmisión de } \\
\text { los papeles sociales (ARIÉS, } \\
\text { 1992; SANTROCK, 2004). }\end{array}$ & $\begin{array}{l}\text { - Institución familiar ausente } \\
\text { o con sus papeles mal } \\
\text { definidos. }\end{array}$ \\
\hline & $\begin{array}{l}\text { - Vías de superación de la crisis } \\
\text { de identidad y construcción } \\
\text { de un nuevo sentido del } \\
\text { yo (ERIKSON, 1989; } \\
\text { SANTROCK, 2004) }\end{array}$ & $\begin{array}{l}\text { - Adolescentes en crisis } \\
\text { permanente sin posibilidad } \\
\text { de superación de ésta por } \\
\text { una vía saludable. }\end{array}$ \\
\hline & $\begin{array}{l}\text { Participación de los } \\
\text { adolescentes en instituciones } \\
\text { sociales (escuela y otras) } \\
\text { (CORRAL y PERINAT, } \\
\text { 2014) }\end{array}$ & $\begin{array}{l}\text { - Jóvenes aislados de la } \\
\text { sociedad. }\end{array}$ \\
\hline
\end{tabular}


Como se ha comentado, Larry Clark representa en sus películas, a los jóvenes norteamericanos autónomos respecto de cualquier figura adulta, viviendo únicamente con su grupo de pares caracterizados por ser irresponsables, violentos, adictos alas drogas y del sexo como un objeto de consumo para una satisfacción inmediata y/o como huida de los problemas, carentes de códigos éticos con sus propias leyes basadas en la violencia y la trasgresión y sin ningún compromiso social o político. Las relaciones familiares son casi inexistentes y los padres son, en gran parte, los responsables de la situación en que se encuentran los adolescentes. Esta manera de representar la adolescencia estadounidense coincide, en estos aspectos, con los estudios científicos de dicha población en los cuales se observa un aumento significativo, en edad cada vez más temprana, de conductas tales como: delincuencia juvenil, consumo de drogas, abandono escolar, precocidad sexual asociada a conductas de riesgo (lo cual genera aumento de embarazos en la adolescencia y propagación de enfermedades sexualmente transmitidas), depresión y suicidio. Así como, también, el aumento de conflictos entre generaciones, la ausencia del diálogo entre padres e hijos y la disminución de la autoridad y control paternal.

Sin embargo, la adolescencia en su filmografía está constituida principalmente a partir de la sexualidad, como si esta imagen fuera capaz de mostrar la propia naturaleza de lo que se considera una etapa más de la vida. Esto es, como si su relación con las drogas y el sexo fuera pura naturaleza atravesada por cierto salvajismo y no hubiera allí, nada del orden de la cultura. Desde esta perspectiva, la identidad adolescente prácticamente no se conjuga en las estructuras siempre abiertas de la cultura sino que se encuentra definitivamente determinada por la biología.

La idea de que la adolescencia o la juventud son etapas del ser humano enteramente definidas por la naturaleza (en el sentido de desarrollo biológico u orgánico - como por ejemplo cuando para explicar determinados actos de los adolescentes se utiliza la frase "es propio de la edad"), tiene implícito la existencia de algo natural, inherente al desarrollo biológico de los seres humanos que determinaría de una vez y para siempre lo que la adolescencia es. ¿Se puede decir que es propio de la adolescencia poner en riesgo la "vida" de los demás y la propia?, ¿Se puede decir que en Kids, el gusto de Tally (el protagonista) por las vírgenes es común a todos los adolescentes y que el tema del SIDA no preocupa a ninguno de ellos?, ¿Se puede decir que todos los adolescentes, de diferente clase social, actúan de la misma manera? 
Cuando la juventud es definida sólo desde esta lógica lo que se pone en juego es la creación de un estereotipo a través del cual se busca conocer y dar a conocer al "otro", pero a través de un proceso de simplificación, generalización y homogenización, en el que la complejidad de la alteridad queda reducida a un conjunto mínimo de signos. Así como también, reduce las causas de la "crisis" de la adolescencia a la ausencia, violencia y abuso sexual en el contexto familiar, donde no encontramos una posibilidad de superación de la crisis, por parte del adolescente. Sabemos que no todos los adolescentes norteamericanos viven esta situación. Diversas causas se entrelazan y actúan de forma interdependientes produciendo diversos efectos.

Ahora bien, ¿Sus películas retratan una noción equivocada de la adolescencia o es ésta la que ha cambiado en la actualidad? Pues, como vimos, esta adolescencia representada por Clark existe en la realidad, pero dentro de un contexto social, político y económico definido, en el caso, por un porcentaje de los adolescentes de clase baja y media-alta de los Estados Unidos.

\section{Consideraciones finales}

De acuerdo con nuestro objetivo de analizar el cine en cuanto vehículo de representación de un determinado contexto sociohistórico y como herramienta pedagógica de reflexión crítica en torno a la realidad, hemos podido constatar que, a pesar de las diferencias encontradas entre la realidad estudiada y su representación fílmica, el autor Larry Clark tiene el mérito de utilizar en su filmografía actores norteamericanos adolescentes no profesionales, lo que le posibilita una mayor aproximación con la realidad del grupo estudiado. Además, el director se basa en historias reales y utiliza mecanismos cinematográficos que le dan a sus películas una gran impresión de realismo. Parafraseando el autor, sus películas son en sí, una crítica a la actual sociedad burguesa norteamericana y sirven como un espejo y alerta de los problemas que ésta afronta. De esta forma, podemos afirmar que el cine es un vehículo de comunicación, influencia y representación sociocultural, a través del lenguaje icónico, y como tal está condicionado por su entorno y refleja el elemento esencial de su época. Su función social permite al hombre comprender la realidad, ayudándole a soportarla y a transformarla.

Sin embargo, en el estudio de la representación de la adolescencia norteamericana, debe distinguirse la realidad (social, política y económica) de la evidencia fílmica (las películas y, por su extensión, su proceso de 
producción, distribución y exhibición). Hay que diferenciar la adolescencia real de su representación fílmica, pero atendiendo a los múltiples puntos de contacto y retroalimentación que las mantienen unidas. El cine, como el resto de las industrias culturales coadyuvantes, forma parte de la misma sociedad que refiere, restituye y proyecta a través de sus mecanismos de representación.

Tal como vimos en el análisis basado en la metodología de Busquets, el cine como forma de representación social, cultural y política del mundo representa la realidad a través de las imágenes icónicas, y por lo tanto difiere de esta misma realidad representada, según las ideas que el autor tiene de la realidad.

Corroborando lo escrito por Busquets, Gombrich señala:

A través del doble camino de la historia del arte y la psicología, ha mostrado cómo el factor clave de la representación no está en la relación de semejanza que pueda establecerse entre el objeto y su representación, sino en que ambos cumplan la misma función. Función de substitución, anterior, lógica e históricamente al retrato-semejanza-donde la creación precede a la comunicación. (Gombrich 1999 citado en ZUNZUNEGUI, 2019, p. 58).

Partiendo de este punto, la representación como substitución precisa dos condiciones: que la forma autorice el significado con el que se le inviste y que el contexto fije el significado de manera adecuada.

Por lo tanto, siempre que hay semejanza hay sustitución aunque la primera no sea condición necesaria para la segunda,

pues como subraya Roland Barthes (1973), la representación no se define por la imitación, y aquella existe más allá de las nociones de real, verosímil o copia. Y esto es así, por la identificación profunda entre representación y significación. (ZUNZUNEGUI, 2019, p. 58).

Desde este modo, conviene dejar claro que el significado no se confunde con el mundo externo. Las diversas expresiones no significan cosas o estados del mundo (aunque puedan remitir a ellas). Los significados se identifican con unidades culturales, con determinados aspectos de nuestra organización del mundo.

En el mundo de la imagen significar es abstraer y extraer, seleccionar, orientar. Debido a que la imagen es selectiva, instaura un punto de vista y reproduce el mundo en un marco delimitado. De esta manera el mundo 
duplicado en la imagen se presenta como algo que existe realmente, pero siempre a través de un conjunto de relaciones determinadas y determinantes. (ZUNZUNEGUI, 2019, p. 178).

Para concluir, quisiéramos hacer algunas consideraciones de carácter más general. Pensando en que este trabajo pueda tener una utilidad práctica. En este sentido, pensamos que el cine constituye un producto de gran valor en las prácticas pedagógicas para apreciar el surgimiento y el desarrollo de un discurso social que habla sobre su cultura, de tal forma que puede contribuir a la comprensión de los fenómenos actuales de producción de sentido. Desde el punto de vista del estudio de los signos, resulta un registro excelente para apreciar el proceso de significación de un hecho histórico y la transformación de las imágenes que lo documentan en íconos dentro de un sistema semiótico, permitiendo además apreciar las alteraciones de estos signos en un proceso de adaptación a nuevos significados hasta su disolución en otros discursos posteriores.

Como se haseñalado al principio de este artículo, la práctica del cine como herramienta didáctica está relacionada con la educación de la mirada, estableciendo una relación directa y funcional entre la imagen y el saber. De acuerdo con Amorin y Bueno (2011),

aprender a analizar la imagen y ver/captar sus conceptos, se refiere sobre todo, verlos en sus distorsiones, en sus insipiencias, no en la búsqueda del concepto real y transparente, si noen la medida en que ver es permitir, ir más allá, en que ver es también crear, en que en el acto de ver ponemos siempre un poco de nosotros mismos. (AMORIN y BUENO, 2011, p. 516).

Por todo ello, consideramos fundamental la utilización del cine en las prácticas pedagógicas como un excelente instrumento para los docentes que les permite fomentar el pensamiento crítico de sus estudiantes y una actividad activa en relación a la sociedad en la cual les ha tocado vivir. 


\section{Referencias}

ALAN GUTTMACHER INSTITUTE, National survey of the American male's sexual habits. New York: Author, 1995.

AMORIN, F., BUENO, R. Tópicos para Pensar a Pesquisa em Cinema e Educação. Educação e Realidade. Porto Alegre, v. 36, n. 2, p. 505-519, maio/ ago. 2011. Disponible en: http://www.ufrgs.br/edu_realidade. Acceso en: 03 junio 2019.

ARIÉS, P. El niño y la vida familiar en el antiguo régimen. Madrid: Ed. Taurus, 1992.

BALARDINI, S.; A. Jóvenes, tecnología, participación y consumo. Proyecto Juventud. Programa Grupo de Trabajo de CLACSO, 2000. Disponible en: http://biblioteca.clacso.edu.ar/clacso/gt/20101023013657/balardini.pdf. Acceso en: 27 mayo 2019.

BAZIN, A. ¿Qué es el cine? (J. L. L. Trans.) Madrid: Ediciones Rialp, 2004. BUSQUETS, L. Para leer la imagen. Madrid: Publicaciones ICCE, 1977. CENTER FOR DISEASE CONTROL AND PREVENTION. Sexually Transmitted diseases. Atlanta: Autor, 2001.

CENTER FOR DISEASE CONTROL AND PREVENTION. Your risk behaviuor surveillance, United States, MMWR, 49 (No. SS-5), 2000.

CORRALIÑIGO, A.; PERINAT, A. et al. Los adolescentes en el siglo XXI: un enfoque psicosocial. Barcelona, Ed. UOC, 2014.

DIElMAN, T. H., Shope J. T., \& Butchat, A. T. Peer, family, and intrapersonal predictors of adolescent alcohol use and misuse. Paper presented at the meeting of the Society for Reaserch in Adolescent, Atlanta, 1990.

DUARTE, R. Cinema \& Educação: refletindo sobre o cinema e educação. 3. ed. Belo Horizonte: Autêntica, 2017.

ERIKSON, E. Identidad, Juventud y Crisis. Madrid: Ed. Taurus, 1989.

FLEMING, J. E., BOYLE, M. \& OXFORD, D. R. The outcome of adolescent depression in the Ontario child health study follow-up. Journal of the American Academy of Child and Adolescent Psychiatry.32, 28-29, 1993 
JOHNSTON, L. D., O’MALLEY, P. M. \& BACHEAN, J. G. Monitoring the Future: 2001. Ann Arbor, MI: Institute for Social Research, University of Michigan, 2001, December 19.

LEVI, G. y SCHMITT, J. C. Historia de los jóvenes. Madrid: Ed. Taurus, 1996.

MARTINS. I. y ESTAÚN, S. Violencia y Cine: percepción y comprensión por los jóvenes. Revista Austral de Ciencias Sociales, 20: 5-18, 2011.

NATIONAL CENTER FOR EDUCATION STATISC. Violence and Discipline problems in U.S. public schools. Washington, D.C.: Author, 1998.

OLIVA, A. Adolescencia en España a principios del siglo XXI. Cultura y Educación, 15(4), 373-383, Sevilla, Universidad de Sevilla, 2003.

PETERSON, P. L. et al. Disentangling the effects of parent drinking, family management, and parental alcohol norms on ocurrent drinking by Black and White adolescents. Journal of Research on Adolescence, 4, 203-228, 1994.

PETTIT, G. S. et al. Antecedents and Behavior-problem outcome of parental monitoring and psychological control in early adolescent. Child Development, 72, 583-598, 2001.

RICHARDSON, J. L. et al. Substance use among eighth-grade students who take care of themselves after school. Pediatrics, 84, 556-566, 1989.

SANTROCK, J.W. Psicología del Desarrollo en la Adolescencia, Madrid: Ed. McGraw Hill, 2004.

ZUNZUNEGUI, S. Pensar la Imagen. Madrid: Catedra/ Universidad del País Vasco, 2019.

Recebido em: 26 ago. 2019.

Aceito em: 12 nov. 2019. 